\title{
Estabilización y problematización. Los nombres en textos literarios de Victoriano Salado Álvarez
}

\author{
Alberto Vital Díaz ${ }^{1}$
}

Resumen. El presente artículo se propone estudiar el uso de los antropónimos en diversos ejemplos de la narrativa del autor mexicano de origen jalisciense Victoriano Salado Álvarez (1867-1931), concretamente a través del análisis de cuatro tipos de textos emblemáticos de su obra: cuentos de tendencia innovadora desde el punto de vista estilístico y discursivo; cuentos de trama convencional; diálogos o textos afines a las convenciones teatrales, y ejemplos de novela histórica, específicamente de sus Episodios nacionales mexicanos (1902-1906). Estos tipos se muestran a la luz de la influencia onomástica ejercida en ellos por una tradición hispánica de raíz cervantina o galdosiana. La hipótesis del artículo consiste en que el uso de los nombres conforma una estrategia ligada no sólo a una poética sino a una visión de la literatura a partir de la cual puede verse un útil campo de análisis de los textos literarios. En un autor afín al realismo de corte hispánico como Salado Álvarez, principios como la estabilidad de los nombres así como la identidad nombrepersonaje a partir de lo que se da en llamar la regla áurea del nombre, contrastan con lo que aquí se tematiza como desestabilización, inestabilidad y problematización en la onomástica literaria, propios de vanguardias posteriores y tradiciones de ruptura.

Palabras clave: nombres; onomástica literaria; estabilidad; desestabilización; problematización; regla áurea del nombre.

\section{[en] Stabilization and Problematization. The Names in Victoriano Salado Alvarez' Literary Texts}

\begin{abstract}
The present paper aims to show the use of anthroponyms in the narrative work of Mexican writer Victoriano Salado Álvarez (1867-1931). The analysis goes through four different types of texts, highly representatives of Victoriano Salado's work: 1) short stories with innovative tendencies from a stylistic or discursive standpoint; 2) short stories of conventional plot; 3) dialogues or theatrical-like texts, and 4) fragments of historical novel, mainly from his work Episodios nacionales mexicanos (1902-1906). These usages are shown in the line of the onomastic influence by a Hispanic tradition with clear traces of Miguel de Cervantes and Benito Pérez Galdós. This paper claims that usage of proper names is closely related not only to a discursive strategy but also to a poetics of literature through which we may see a useful field of inquiry of literary texts. In an author such close to realism of Spanish tradition as Salado Álvarez, formal principles like stability of names as well as the identity "name-character", through which here we call the Golden rule of name, are set into contrast with other principles like destabilization, instability and problematization in the literary onomastics, closer to subsequent avant-garde traditions in literature.
\end{abstract}

Keywords: names; literary onomastics; stability; destabilization; problematization; Golden rule of name.

Sumario. 1. Recapitulación. 2. Necesidad de innovación. 3. Creciente influencia del periodismo en la lectura literaria. 4. Estructura de "De autos". Doble interdiscursividad. 5. Los nombres en "De autos": rutina e innovación. 6. Nombres estables y estabilizadores. 7. La desestabilización del vínculo nombre-personaje como recurso. 8. Desestabilización y problematización en la vanguardia mexicana. La Señoria Etcétera (1922). 9. De la desestabilización a la problematización. Regla áurea del nombre propio. 10. Problematización en la vida fáctica. 11. Nombres específicos como problema y problematización. 12. Estrategias de pregnancia. 13. Otros tipos de desestabilización en Salado Álvarez. 14. Inestabilidad y desestabilización. 15. El novelista histórico. 16. El heredero de Cervantes y Galdós. Nombres característicos. 17. El autor de diálogos y de escenas. 18. Conclusiones.

Cómo citar: Vital Díaz, A. (2021) Estabilización y problematización. Los nombres en textos literarios de Victoriano Salado Álvarez, en Anales de Literatua Hispanoamericana 50, 125-137.

\footnotetext{
${ }^{1}$ Universidad Nacional Autónoma de México. México.

Email: avital@cepe.unam.mx
} 
En modesto homenaje al gran maestro Álvaro Matute (1943-2017), esencial presencia para quienes tenemos el privilegio de vivir en esta casa universitaria.

Si para todo hay término y hay tasa y última vez y nunca más y olvido, ¿quién nos dirá de quién, en esta casa, sin saberlo, nos hemos despedido?

Creo en el alba oír un atareado rumor de multitudes que se alejan; son los que me han querido y olvidado; espacio, tiempo y Borges ya me dejan.

("Límites", Jorge Luis Borges)

\section{Recapitulación}

Haré un brevísimo repaso para quienes no conocen las últimas publicaciones en torno a Victoriano Salado Álvarez ni el contexto literario general donde se inscribe el cuentista. El texto "De autos", primero en el libro homónimo y uno de los primerísimos del jalisciense en publicarse, es insólito porque renuncia al narrador omnisciente, típico de toda la literatura mexicana del siglo XIX, y sobre todo porque es interdiscursivo desde el momento en que se estructura mediante los protocolos de un género distinto al cuento: el auto o acta ministerial. Ambos rasgos -especialmente el segundo- eran inéditos en nuestra literatura y se adelantaban al menos unos veinte años, si no es que cincuenta, a las prácticas que crearon y realizaron las vanguardias de los años veinte y de los cincuenta-sesenta tanto en nuestro país como de hecho en numerosas partes del mundo.

Ahora bien, si "De autos" es innovador, estamos entonces ante una muestra de poética asimismo innovadora. ¿Los nombres propios de lugares y personas contribuyen a una poética original en aquellos inicios del siglo XX, cuando el Modernismo había traído aires frescos a los versos y cuando el realismo de Rafael Delgado y el inminente naturalismo a la mexicana de Santa de Federico Gamboa representaban una cierta puesta al día de nuestra novela en los contenidos, no así en la forma, mientras que se habían pasado por alto las propuestas de Manuel Gutiérrez Nájera en Por donde se sube al Cielo y mientras el cuento modernista daba indicios asimismo de una experimentación que apenas despuntaba?

Contrario al Modernismo por todo lo que éste había tenido de decadentismo a principios del último decenio del siglo XIX, Salado exploró con "De autos" una renovación formal desde el realismo y para el realismo, convencido como estaba de que el realismo de raíz hispana (Cervantes, Galdós, Pereda, Pardo Bazán) y el nacionalismo ético y estético (propuesto en México por el maestro Ignacio Manuel Altamirano) bastaban como repertorios de temas y de formas para sacar adelante una literatura que en aquel entonces (a falta de cine y de todas las otras alternativas de representación estética y dramática que durante el siglo XX y el XXI se han apoderado del público masivo) era la proveedora casi exclusiva de símbolos, figuras y relatos para el imaginario colectivo, aunque es verdad que el periodismo le robaba terreno a la literatura, y los escritores hicieron con el periodismo lo que cincuenta años después hicieron los autores de medio siglo con el cine: se esforzaron por practicarlo, en parte para ganarse la vida, en parte para aprender técnicas y en parte para beneficiarse del creciente capital simbólico acumulado por la industria fílmica, especialmente durante la época de oro del cine nacional.

\section{Necesidad e innovación}

Aun cuando Salado chocó en polémicas con los decadentistas o modernistas, de cualquier modo compartió con ellos el "nerviosismo" (palabra muy de época) que provocaron las transformaciones industriales, el crecimiento de la población y las nuevas técnicas aplicadas a la comunicación masiva. Estas técnicas servían tanto a una vertiginosa producción física o material como a una también vertiginosa, si no es que ansiosa, producción simbólica, discursiva, cada vez más presente en el tiempo libre de la de por sí escasa población alfabetizada y -sobre todo- letrada, por lo común reunida en los corazones políticos y económicos de las crecientes metrópolis latinoamericanas. 


\section{Creciente influencia del periodismo en la lectura literaria}

Aunque no lo reconociera francamente, Salado también experimentó el vértigo de la nueva época. Se multiplicaban las denuncias públicas contra aspectos disfuncionales de la vida social, política o económica. El periodismo mexicano inauguraba con Manuel Caballero la veta de la nota roja, esto es, del reportaje incisivo sobre crímenes "sensacionales" (otra palabra de época), es decir, sobre hechos de sangre que provocaban una sensación de impacto duradero.

"De autos" deja leerse en el trasfondo de una nueva costumbre: la gente leía por entregas los avances de las pesquisas policíacas en torno a crímenes más o menos famosos. Buena parte del impacto se lograba mediante una construcción discursiva que se amparaba en tres rasgos novedosos: 1) la crudeza de un "objetivismo" reforzado por fotografías que, aunque a veces borrosas, aproximaban a los lectores a la "realidad" misma, a "los hechos"; 2) la ausencia o al menos mengua de un mediador que hiciera juicios al respecto, pues al parecer los hechos podían hablar por sí solos, y 3) la presentación de la noticia como una secuencia o serie de actualizaciones día a día, si no es que de la mañana a la tarde o de la tarde a la noche.

\section{Estructura de "De autos". Doble interdiscursividad}

La estructura de "De autos" responde perfectamente a esta tendencia de géneros que, aunque no literarios, aun así estaban influyendo en la visión del mundo de escritores como Salado Álvarez: de modo cada vez más característico y típico, el jalisciense era lector de periódicos, era colaborador en periódicos y sabía que sus lectores leían periódicos. De hecho, su propia vida quedó marcada por el periodismo, pues si se trasladó de Guadalajara a México fue por la invitación en 1899 del oaxaqueño Rafael Reyes Spíndola, hábil periodista y director de empresas noticiosas, figura clave en el control político durante la dictadura de Porfirio Díaz.

En síntesis, "De autos" delata una doble interdiscursividad: no sólo se apropia 1) de rasgos específicos y protocolos (secuencias en que se presentan esos rasgos) del género judicial llamado "auto" o "acta" de ministerio público, sino 2) de rasgos y protocolos del género periodístico llamado "reportaje policíaco" o "nota roja". 2

La edición original en libro y pocos meses después en periódico reforzaba esta intención, pues las ilustraciones jugaban con un aspecto típico de la edición impresa de noticias: en las publicaciones periódicas las imágenes eran muchas veces, no sólo fotografías, sino dibujos a cargo de personalidades del pincel y del lápiz, como Julio Ruelas en la Revista Moderna y como un buen número de artistas mexicanos y extranjeros en El Mundo Ilustrado. ${ }^{3}$

\section{Los nombres en "De autos": rutina e innovación}

Pues bien, los nombres en "De autos" se emplean de un modo que no es innovador para nuestro horizonte del siglo XXI, acostumbrado desde hace mucho a una narrativa de indagación de crímenes. Pero en el México de fines del XIX esta narrativa apenas se asomaba, así que el inicio del texto con 1) un ser humano que no puede decir su nombre y, por lo tanto, con 2) un nombre que ha de buscarse, resultaba más bien fresco y relativamente poco usual.

Dicho de otro modo, el recurso del nombre aún por indagarse es convencional y hasta rutinario si se considera la perspectiva del macro-género de la indagación de un crimen (donde se ubican géneros como la novela policíaca y el cuento asimismo policíaco), pero en ese momento era no convencional y no rutinario si

${ }^{2}$ La primera de estas dos interdiscursividades ya aparece apuntada en Alberto Vital, "Introducción” (Salado, 2013: XLIII-XLIV). El presente análisis es más extenso y focalizado que el que esbocé allí. A propósito del estilo de "De autos" merece leerse la observación de un jurista consumado, José Ramón Cosío: “Algo que me importa resaltar es que en ningún tiempo existe algo así como la 'neutralidad' en el modo de la redacción de las sentencias. // Uno de los mejores ejemplos que he podido apreciar al respecto es el breve cuento de Victoriano Salado Álvarez "De autos", publicado originariamente en 1901 en el libro De autos. Cuentos y sucedidos (Guadalajara, Impresora de J. R. García y Hno.) [...] En él se demuestra la manera en que una 'mera' narración, aparentemente 'neutral y técnica', en realidad está hecha para tener implicaciones brutalmente específicas. Agradezco al profesor Fernando Escalante el haberme dado a conocer este cuento y señalado sus implicaciones” (Cosío, 2014: 139140).

${ }^{3}$ Se sabe bien que El Mundo Ilustrado (1894-1914) fue dirigido en su época de oro (1894-1908, especialmente 1904-1908) por Rafael Reyes Spíndola y fue un espacio de expresión de las élites porfiristas y de divulgación de los modelos que dichas élites consideraban esenciales en la moda, las artes, los patrones de conducta y desde luego la obediencia a las altas autoridades políticas, con Porfirio Díaz a la cabeza. Véanse para ello trabajos indispensables como (Saborit, 2003) entre otros. 
se considera el contexto mexicano:

En el pueblo del Huizache, a los veinte días del mes de febrero de mil novecientos, habiéndose recibido la adjunta consigna, se pasó al punto conocido como Corral de Piedra, distante como un kilómetro del lugar, y se da fe haber visto el cadáver de un hombre como de veintidós años de edad, alto, moreno, con un ligero bozo en el labio superior, cabellos, cejas y ojos negros; presentaba en la región precordial un agujero producido por la entrada de una bala, proyectil que tenía su orificio de salida en el omóplato izquierdo, y otra herida de sable hacia el frontal, midiendo la lesión once centímetros de tamaño por uno de anchura; la profundidad no se pudo medir por no contarse con instrumentos apropiados para ello(Salado, 2013: 1). ${ }^{4}$

Estamos aquí ante una de las situaciones básicas del relato de indagación de crimen: un cadáver y una ausencia de nombre. La ausencia de nombre implica una ausencia de identificación y un desconocimiento de identidad acaso momentáneo. Un relato puede requerir de un alto porcentaje de su desarrollo (hasta el clímax, por ejemplo) para que se alcance la plena identificación del personaje y se establezca la indudable identidad del mismo, como es común en relatos policíacos de Arthur Conan Doyle y Agatha Christie.

En este texto saladiano dura muy poco el vacío de información provocado por la falta de nombre: pronto el lector implícito sabe cómo se llamaba el joven y deduce que la tarea de llenar ese vacío no será la columna vertebral de la trama. De hecho, los nombres (tanto topónimos como antropónimos) cumplen a lo largo del texto una tarea fundamental de todos los apelativos propios en los textos: ayudar a la comprensión de la trama y de las intenciones del autor mediante la garantía de que existe un elemento estable a lo largo del texto, no importa si este último se alarga por cuatro páginas o por cuatrocientas.

\section{Nombres estables y estabilizadores}

Los nombres propios, en efecto, son las palabras más estables y constantes en un altísimo número de textos: su estabilidad es clave para la comprensión de la trama en un proceso de intenso y permanente dinamismo. Escribe Dieter Lamping:

Eine Figur identifizieren heisst nicht nur, sie in einer Situation von anderen unterscheiden, sondern auch, sie in allen möglichen Situationen wiedererkennen zu können. Voraussetzung dafür ist, über die Eindeutigkeit der Namenzuordnung hinaus, ihre Konstanz (Lamping, 1983: 23). ${ }^{5}$

Podemos imaginar un texto en el que se narraran las acciones, pero nunca se especificara quién las hizo: al lector se le impondría la tarea de ir asignando o atribuyendo acciones según parecieran corresponderle a este o a aquel personaje que el propio lector iría inventado. Los nombres propios le ahorran este trabajo. Sin los nombres, la literatura dejaría de existir. ${ }^{6}$

\section{La desestabilización del vínculo nombre-personaje como recurso}

A la vez ha de decirse que son numerosos los textos y hay más de un género (los policíacos y la comedia de

\footnotetext{
${ }^{4}$ Por lo demás, hay géneros discursivos que sólo funcionan si el autor sigue las correspondientes rutinas, que se vuelven auténticos protocolos, esto es, pasos que los lectores o receptores esperan. Desde ese punto de vista, es positivo que el autor de texto de indagación de un crimen siga los protocolos y evite desviaciones de un uso en trance de volverse norma; del mismo modo, el lector de nota roja no esperaba una larga arenga moral o una contextualización histórico-antropológica a la hora de leer los avances de la indagación de un crimen.

${ }^{5}$ Identificar un personaje no significa sólo poder distinguirlo de los otros en una situación, sino poder reconocerlo de nuevo en todas las situaciones posibles. Una condición para ello es la univocidad del nombre, la constancia [traducción del autor].

${ }^{6}$ Una despersonalización, ya que no necesariamente deshumanización, de la escritura literaria se acompañó de una tendencia a la despersonalización en la pintura y otras artes desde la segunda mitad del siglo XIX. Una parte importante de la poesía mexicana se escribe aún hoy conforme a una poética que podría ejemplificarse con Blanco (1966), de Octavio Paz: en numerosos poemas no hay un yo, un tú, un conjunto de estables nombres propios. En esos casos sí estamos ante el imperativo para el lector de armar un rompecabezas, luego de decidir si es que existe ese rompecabezas. Podría incluso hablarse de dos grandes corrientes en la poesía mexicana a partir de las vanguardias: una tendencia a la fragmentación de la identidad del yo y del tú lírico (y en general de cualquier personaje) y una tendencia a la conservación de la identidad e identificación de las voces en el texto. En la primera gran tendencia se encuentran el Octavio Paz de madurez (Blanco en adelante) y Jaime Augusto Shelley; en la segunda, el joven Paz, Rubén Bonifaz Nuño y Jaime Sabines. En prosa, el Arqueles Vela de La Señorita Etcétera, el Gilberto Owen de Novela como nube y la prosa vanguardista de Efrén Hernández bastan como ejemplos.
} 
enredos, por ejemplo) en los que la desestabilización del vínculo entre nombre y personaje es un recurso no sólo común, sino necesario e incluso intrínseco, inherente al género. En "De autos" acabamos de ver un ejemplo del tipo más elemental y primario de desestabilización: aquel en el cual un personaje no puede o no quiere decir su nombre. Otro tipo elemental y básico es el exacto opuesto: tenemos el nombre, no al portador del nombre.

El siglo XX ensanchó estas posibilidades de la mano de las crecientes dudas acerca de la estabilidad de las respectivas identidades individuales en el marco de la masificación de la sociedad y de la industrialización extrema de la guerra, con asesinatos en masa (genocidios, exterminios) que volvían irrelevante al individuo precisamente cuando se buscaban implantar los derechos humanos y extender los dominios del respeto a cada persona específica.

Más allá de los géneros policiacos y de la comedia de enredos, las novelas de Samuel Becket convirtieron el nombre propio no sólo en parte estructural y estructurante del argumento, sino en el argumento mismo, pero para eso rompieron toda posibilidad de asignarle una identidad estable a un personaje, en este caso el propio narrador, dubitativo en extremo acerca de su propia identidad y de la conveniencia de portar tal o cual nombre.

Los narradores de Becket parecen estar buscando una relación esencial nombre-portador del nombre y así toman una postura clara en un debate que se remonta por lo menos al Cratilo de Platón y que desde Ferdinand de Saussure pareció quedar zanjado a favor de la relación arbitraria entre nombre común o propio, por una parte, y objeto o ser vivo, por la otra.

Sólo que la solución de Saussure a fines del siglo XIX y principios del XX pasa por alto la enorme complejidad o por lo menos variabilidad o diversidad de la relación de una persona o personaje con su propio apelativo. La narrativa y el teatro de Beckett son una aguda exploración de la pérdida de identidad, de lugar en el mundo y del sentido mismo de la existencia, y en todo esto es significativo que los nombres y su arbitrariedad o su ausencia se conviertan en un recurso constante, en un referente.

\section{Desestabilización y problematización en la vanguardia mexicana. La Señorita Etcétera (1922)}

Ya desde las vanguardias la literatura mexicana exploró las posibilidades literarias de la desestabilización constante (sin solución final, como en el relato policíaco clásico) y de la problematización:

En mi imaginación ya no existía solamente ella, no era solamente ella; se fundía, se confundía con esta otra ella que me encontraba de nuevo en el rincón de un café (Vela, 1991: 58).

No me quedaría de ella, sino la sensación de un retrato cubista. Una pierna a la moda con medias de seda, ruborizada de espejos $(60)$.

A pesar de que su transformación había sido sistemática, yo estaba seguro de que, en el fondo, ella seguía pensando con los pensamientos míos (63).

Esta novela corta no incluye un solo nombre propio, excepto el del título. Al final hay una repetición de "etcétera" en una rápida secuencia de frases, y antes hay una alusión expresa a puntos suspensivos, muy frecuentes por cierto en el texto. "Etcétera" y los suspensivos forman parte de un mismo campo del discurso: aluden a una extensión o prolongación indeterminada del propio discurso, preferentemente escrito (en expresiones orales los suspensivos sólo pueden manifestarse si se los menciona de modo explícito). Aun así, hay un notorio vacío de información en los nombres entre el título y el texto, además de que el nombre en el título es insólito y apunta a la indeterminación, a la prolongación indefinida que ya está de por sí expuesta en los semas de "Etcétera". Cuando vacíos como éstos no se llenan, le queda al lector la tarea de resolver la desestabilización y la problematización correspondientes; en otros términos, el autor implícito de La Señorita Etcétera ha resuelto que la ruptura de la regla áurea del nombre propio quede como un problema para el lector implícito.

\section{De la desestabilización a la problematización. Regla áurea del nombre propio}

Con estos ejemplos hemos transitado ya desde una desestabilización hasta una auténtica problematización del nombre.

Propongo definir desestabilización del nombre como un recurso más o menos convencional presente en 
numerosas narrativas y dramatizaciones, consistente en la ruptura momentánea o temporal de la regla áurea de la identidad nombre-personaje, siempre con el fin de crear suspenso y en general de contribuir a que la trama sea posible.

La regla áurea es la identidad estable e indudable de un personaje con su respectivo nombre, el cual es inconfundible; cuando en la vida de carne y hueso o en el mundo de un texto se asoma una posible confusión (dos personas o personajes con un mismo nombre; dos nombres para una sola persona o personaje, por ejemplo), entonces la lengua y la onomástica práctica disponen de un mecanismo muy sencillo para evitarla: se añade un término al nombre, ya sea un nombre de pila más o un segundo apellido o un apodo o un gentilicio o patronímico. De ese modo, el nombre de un término, Zenón, se vuelve en nombre de dos términos: Zenón de Elea.

La problematización del nombre es una desestabilización extrema, durable, de la regla áurea, ya no sólo para efectos de la trama, como en el relato policíaco, sino por motivaciones como las ya señaladas -pérdida y búsqueda de identidad- y otras como exploración de los mecanismos de construcción del texto, experimentación, provocación al lector, desautomatización de los hábitos de escritura y lectura.

\section{Problematización en la vida fáctica}

Antes del registro civil plenamente institucionalizado y automatizado, las personas sufrían enormes problemas con sus nombres. Esta situación se volvió muy aguda entre quienes nacieron en épocas previas a la institucionalización plena y a la automatización del registro y han alcanzado a vivir en estos tiempos, en los cuales se presupone que toda la gente cuenta con un registro digitalizado. De ese modo, la literatura puede tomar la problematización de la vida fáctica, aunque no necesariamente tome los mismos casos, tal y como se presentan en el día a día.

\section{Nombres específicos como problema y problematización}

Salado nunca llega tan lejos. No hay problematizaciones del nombre en su obra. Ahora bien, ha de revisarse un matiz entre el hecho de que portar un determinado apellido sea un problema al interior del mundo narrado y el hecho de que el narrador heterodiegético o alguna voz problematice el vínculo nombre-personaje, esto es, la regla áurea de la identidad.

El célebre monólogo de Julieta ante el apellido de Romeo es un paradigma de ambas cosas a la vez: 1) de problema de un apellido específico y 2) de problematización del nombre en general (¿Por qué, a fin de cuentas, hay que portar un nombre?):

JULIET 'Tis but thy name is my enemy:

Thou art thyself, though not a Montague.

What's a Montague? It is nor hand, nor foot,

Nor arm, nor face, nor any other part

Belongin to a man. O, be some other name!

What's in a name? That which we call a rose

By any other name would smell as sweet;

So Romeo would, were he not Romeo call'd,

Retain that dear perfection which we owes

Without thy title, Romeo, doff thy name,

And for that name which is no part of thy

Take all myself.

(Shakespeare, 2016: 109) ${ }^{7}$

\footnotetext{
7 “JulieTA Tan sólo tu nombre / es mi enemigo. Tú eres tú mismo. / Ya no eres un Montesco. / ¿Qué es un Montesco? No es ni pies ni mano, / brazo ni rostro, ni cualquier otra parte / que pertenezca a un nombre. / Oh, sea otro tu nombre porque, ¿qué es un nombre? / Lo que llamamos rosa olería / tan sabroso con cualquier otro apelativo; / lo mismo que Romeo, si Romeo no se llamara, / retendría la cara perfección / que posee ahora sin tener tal título. / Romeo, quítate tu nombre, y a cambio de él / que no es parte tuya, toma todo mi ser” [Traducción del autor]
} 
La argumentación de Julieta es óptima para el análisis porque por una parte expresa una suerte de naturalismo absoluto y un derecho natural basado en una comprensión de (y casi más bien una compenetración con) la naturaleza y sugiriendo los derechos del amor natural, vale decir, animal, instintivo, y a la vez humano y sutil, capaz de argumentar finamente contra una de las acciones intrínsecas de nuestra especie: el nombrar; y por la otra exhibe una debilidad argumentativa que no es tal para su visión "natural" y, por así decirlo, "jusnaturalista" porque no puede admitir que para una visión cultural y una práctica contractual (un hábito o serie de hábitos que se desprende de un contrato explícito o tácito) el poseer un nombre es una determinación y es un símbolo de una serie de condiciones y condicionamientos y de desventajas y por supuesto también de ventajas como aquellas de las que ella misma ha disfrutado por ser una Capuleto, esto es, hija de una de las familias de la élite de la ciudad. Estamos entonces ante la pugna entre la naturalidad plena, corporal y emocional, y las arraigadas convenciones sociales. La contradicción es trágica porque es insoluble. Y es insoluble desde el momento en que Julieta no la advierte en virtud de que su inexperiencia y su horizonte emocional no se lo permiten.

En suma, el parlamento de Julieta involucra dos aspectos: 1) el problema de llamarse de un modo y no mejor de otro menos conflictivo o comprometedor y 2) el problema de tener un nombre en tanto que determinante y control social. Esto último nos confirma que el nombre es una convención social; de hecho, es una de las convenciones sociales más influyentes, mientras que el amor como el que sienten Romeo y Julieta es la expresión misma de lo natural, de lo empático por excelencia, del principio del placer y del instinto de supervivencia de la especie, esto último en la medida en que el amor conduce a la procreación. La tragedia obedece, como en Antígona según el célebre análisis de Hegel, a una lucha entre dos sistemas de convivencia cuando entran en contradicción: el amor inmediato e incontenible y las condiciones sociales que se desprenden de los arreglos y acomodos entre distintos grupos de poder, en este caso familias influyentes. Por lo demás, Julieta desliza un matiz inconsciente al elegir la rosa como paradigma de lo natural: la rosa vive muy poco, tan poco como puede vivir una relación humana en la que no se involucran nombres.

En el cuento "Las nalgadas" Salado Álvarez usa un esquema parecido, que también aparecerá en "El hombre", de Juan Rulfo: dos familias, los García y los Ceballos, pelean a muerte. Allí se confirma que el apellido en sí mismo no es un problema, ni el portar un nombre, ni la identidad provocada por la estable relación entre nombre y personaje que lo porta. Al contrario, en conflictos entre familias la identidad se fortalece porque la estabilidad del nombre es clave para la distinción entre un aliado fraterno y un enemigo a muerte. Desde luego pueden producirse desestabilizaciones del tipo "no sé si este es un García", pero tales desestabilizaciones son recursos para crear una trama interesante.

\section{Estrategias de pregnancia}

En mi artículo "Primeras menciones. Estrategias onomásticas en 'Nos han dado la tierra', 'La Cuesta de las Comadres' y Pedro Páramo, de Juan Rulfo", considero que para un autor resulta clave conseguir que el lector retenga tan pronto como sea posible la identidad de un personaje mediante un nombre inconfundible. Este principio general es una tendencia muy alta en la narrativa y el drama e incluso la lírica y equivale al esfuerzo de una persona de carne y hueso para memorizar el nombre de otra persona. En la vida diaria tal esfuerzo no se encuentra formalizado de ningún modo, esto es, no existen cursos de memorización de nombres ni estudios al respecto y ni siquiera conversaciones o charlas informales articuladas, más allá de alguna mención esporádica o alguna anécdota suelta en una charla. La gente, eso sí, tiene cada vez más posibilidades de imponerles nombres llamativos a sus hijos, del tipo de aquellos que el estudioso alemán Dieter Lamping llama "estéticos" para ciertos personajes con nombres muy eufónicos o insólitos o incluso cómicos. ${ }^{8}$ Aquí tendríamos un intento de pregnancia compartido por la vida fáctica y por la literatura. ${ }^{9}$

Ahora bien, las estrategias de pregnancia y sus tipos son muy variados. Hasta donde sé, no se estudian y por lo tanto son más bien un campo nuevo, promisorio entre otras razones porque pueden arrojar luz

\footnotetext{
8 "La selección de nombres estéticos llamativos es una operación del narrador [o, más precisamente, del autor implícito], lo mismo que el juego cómico con nombres; ambas operaciones deben orientar la atención del lector hacia el nombre como signo verbal. El nombre no pierde con estas operación su función de representación y de denominación, pero estimula su función estética” (Lamping, apud Vital, 2015: 54).

${ }^{9}$ Escribo en "Primeras menciones. Estrategias onomásticas en Juan Rulfo": "De acuerdo con la teoría Gestalt y con otros enfoques de teoría del diseño y de la imagen, por pregnancia se entienden aquí dos cosas: recursos para 1) atraer la atención del espectador hacia una figura, imagen o frase (en último término, cualquier elemento semiótico o lingüístico) y 2) provocar efecto de impregnación, esto es, de tanta persistencia en la memoria como sea posible; en síntesis, se busca efecto inmediato y más o menos mediato" (Vital, 2017: inédito).
} 
justamente sobre la relación entre nuestro mundo en general y los mundos posibles de la literatura.

Ha de partirse de la hipótesis de que el respectivo autor implícito siempre considerará estratégico el carácter y el uso del nombre y de que, como parte de una estrategia general, tanto la primera mención como la pregnancia serán decisivas. Veamos algunos ejemplos en Salado, susceptibles de convertirse en tipos.

\section{Otros tipos de desestabilización en Salado Álvarez}

El ejemplo ya revisado es, sí, uno de los tipos más comunes de pregnancia: ¿cómo se llamará esa persona asesinada o fallecida en un accidente o muerta repentinamente en un sitio donde nadie la conoce? Por cierto que "De autos" ya no resalta más los nombres, y éstos tienden a ser simplemente 1) identificadores, 2) portadores de efecto de real y 3 ) característicos. Estas tres tareas son las más comunes en un nombre propio; de ese modo, las estrategias de nominación en este texto saladiano propenden a cierta rutina, por lo demás muy funcional y, por muchos conceptos, suficiente. En otras palabras, las diversas intenciones estratégicas en torno a un nombre pueden tender a un grado cero, a una rutina, y en tal caso no es que desaparezcan: es que simplemente son aquellas mismas que muchos otros escritores han empleado antes.

Una estrategia de pregnancia muy común consiste en colocar el nombre en alguno de esos lugares privilegiados (Hamon, 1989) o peritextos (Genette, 2001) que son llamativos e incluso atractivos por el sitio que ocupan en la portada o en la primera página del texto. Sabemos bien - o lo intuimos - que un nombre propio en una portada es indicio de la intención en el autor implícito de contar o representar en el texto el destino final y definitivo del personaje o por lo menos la caracterización que nos permita saber cuál será a fin de cuentas ese destino.

"Oportunismo" es el segundo texto de De autos, único volumen de cuentos publicado en vida de Salado. La poética y las intenciones son radicalmente distintas a las de "De autos". Esto incluye las estrategias en la nominalización. Desde un principio hay una identificación nombre-personaje que no se pierde nunca y que de hecho nos lleva a la conclusión de que no existe ninguna desestabilización del nombre y mucho menos problematización en este cuento, al menos en cuanto se refiere al protagonista. Y es que se presenta, eso sí, una cierta inestabilidad que es fruto de la erudición de Victoriano Salado Álvarez: el autor presupone que el lector debe saber mucho acerca de los más diversos epítetos asignados a las figuras históricas que suelen aparecer de pronto para reforzar la ambientación (erudita, sobre todo por las referencias literarias e históricas), la caracterización y, en general, las diversas estructuras e intenciones de los textos del jalisciense. De hecho, una tarea constante de la edición crítica ha consistido en referirle al lector contemporáneo aquellos epítetos que para el erudito Salado y para muchos lectores cultos de entonces resultaban más o menos evidentes.

De ese modo, se impone distinguir entre inestabilidad y desestabilización.

\section{Inestabilidad y desestabilización}

Conforme al ejemplo anterior, inestabilidad en el nombre consistiría en un vacío o incertidumbre en el plano de las relaciones entre el autor y el lector; dicho vacío de información no tendría que ver con la estructura narrativa, sino con la estructura semántica y eventualmente con la estructura apelativa, esto último porque el lector se vería convocado a hacer gala de una erudición a la altura de lo que el autor estaría esperando de él. Sin embargo, asimismo puede ocurrir que la estructura apelativa se complique más allá de las intenciones del autor y que la estructura semántica se vuelva más densa, más opaca, simplemente porque el autor no imaginó que la gente dejaría de saber algún día que a Francisco de Asís se le conocía como "seráfico" y como el "solitario del Monte Albernia":

De familia hidalga, aunque con más pergaminos que doblones y más humos que bienestar, [fray Antonio de Arzola] tomó en su tierra, una famosa ciudad de Andalucía, el santo hábito de la religión seráfica ${ }^{10}$ más bien por no sacar mentiroso aquel refrán de convento, mar o casa real, que porque sintiera su alma pequeña y apegada a las cosas terrenas llena de aquel amor que sentía hacia todo y hacia todos el solitario del Monte

10 "Suele darle el calificativo seráfico a San Francisco de Asís y a la orden religiosa que fundó” (Salado, 2013: nota 5). 
Albernia (Salado, 2013: 8). ${ }^{11}$

En todo caso, cualquier autor podría tener en cuenta que la erudición no se reparte con la misma medida entre la población de lectores, y entonces las referencias eruditas no estarán haciendo otra cosa que disminuir el número de los mismos.

Por su parte, desestabilización sería un recurso al interior del mundo narrado, y si bien todo cuanto ocurre en dicho mundo está concebido para que afecte al lector implícito y acabo de decir que la inestabilidad atañe a la relación autor-lector, aun así propongo aquí que situemos la inestabilidad en los nombres dentro del texto literario como un problema del repertorio cultural vivo y activo, vigente, más o menos aleatorio, más o menos previsible, mientras que una desestabilización formaría parte intrínseca de las tres estructuras básicas del texto (narrativa, semántica y apelativa) y se encontraría entre las intenciones intrínsecas del autor implícito. En resumen, la inestabilidad en la onomástica literaria sería un fenómeno cultural-comunicativo, mientras que la desestabilización sería un recurso textual y literario.

Por lo demás, entre inestabilidad y desestabilización existe la misma diferencia que existe entre estado y proceso, entre dato inmóvil y dinamismo relevante. De ese modo, debo admitir que si en un texto hay una circunstancia o un recurso o un estado de cosas que permanece inestable de principio a fin, habré de reconocer que la inestabilidad es un aspecto que existe en el texto. Sin embargo, el texto es dinámico y los elementos inestables o bien eran al principio estables y quedan rotos al final o bien eran inestable al principio y se recomponen y estabilizan al final.

Más aun, podría postularse que una diferencia entre la vida fáctica y el mundo interno del texto consiste en que nuestra vida tiene una cantidad importante de aspectos que permanecen inestables y son fuente de conflictos y aun así no los percibimos hasta que estallan (y aun así las subsiguientes interpretaciones difieren en cuanto a las causas y los efectos), mientras que el texto literario se escribe justamente para desestabilizar una situación aparentemente estable o para terminar estabilizando una situación paradigmática que es inestable por ser conflictiva.

Y ello no significa de ningún modo que la vida no sea dinámica, sino que lo es en tal exceso que casi nunca podemos seguirla en todas y cada una de las implicaciones y consecuencias de un acto. ${ }^{12}$

De cualquier manera, Salado es un autor circunscrito a una época, y "Oportunismo" es un ejemplo de narrativa tradicional, con un narrador omnisciente que opina y controla y con una historia lineal, clara y distinta. Conclusiones a partir de un cuento de este tipo ayudan a esclarecer estrategias dentro de la tradición más larga y común, conforme a la cual tanto la inestabilidad como la problematización pueden ser recursos intrínsecos, lo mismo que la estabilización y la resolución de problemas en el nombre.

\section{El novelista histórico}

Sabemos que la novela histórica ha experimentado renovaciones significativas en los últimos decenios. De una manera muy general puede hablarse de dos grandes corrientes: novela histórica clásica, inaugurada por Walter Scott y otras voces, y nueva novela histórica, trabajada por muchos autores desde por lo menos la segunda mitad del siglo XX. Pues bien, al tratar acontecimientos como el Segundo Imperio mexicano Victoriano Salado Álvarez se inscribe en la primera tendencia, mientras que Fernando del Paso se apunta en la segunda.

Los Episodios nacionales mexicanos (1902-1906), de Salado, se dividen en dos grandes partes: De Santa Anna a la Reforma y La Intervención y el Imperio.

La edición crítica resalta todos los peritextos que anteceden al texto central de la narración. En ellos ya aparecen nombres propios. De hecho, allí empiezan a manifestarse los dos grandes tipos de nombre en el ciclo novelístico de Salado: los de personajes históricos y los de personajes ficticios, inventados. Se conoce que en la construcción de personajes en la novela histórica (clásica) se mezclan personajes conocidos de la vida real, pertenecientes a las élites, y personajes inventados por el autor. A este esquema se atiene Salado desde el arranque:

\footnotetext{
11 "La estigmatización de San Francisco se representa típicamente en el Monte Albernia" (Salado, 2013: nota 7).

12 Jorge Luis Borges explicó esta condición que ya había ocupado a Gilbert K. Chesterton: tomar un puño de arena del Sahara y arrojarlo al aire es un acto simple cuyas repercusiones pueden ser incontables y por lo tanto irrecuperables en una figura, salvo quizá la de algún tipo de laberinto (e incluso los laberintos adoptan, en efecto, más de una figura) (Borges, 1989: 445).
} 
Ya viejo y con un mediano pasar, ocioso, amante de los libros y dueño de algunos muy lindamente escritos; sin mujer, hijos ni nietos a quien cuidar, debería retirarme a mi casita de La Sauceda y aguardar allí la muerte, que naturalmente no debe dilatar en venir. [...]

Me llamo Juan Pérez, tengo sesenta y nueve años de edad (que cumpliré el próximo veinticuatro de noviembre, día del bienaventurado Juan de la Cruz). Mis padres, contrariando la sentencia del clásico, fueron pobres y honrados; mi linaje es oscuro, pero de gentes buenas y que nunca dieron que hacer a la justicia.

No puedo injertar mi árbol genealógico por rama ninguna con la de los siete infantes de Lara o el Cid Campeador: el primer ascendiente mío que vino a estas tierras se llamaba Pero Pérez de la Llana, era castellano viejo, de tierras de Burgos, y por no sé qué azares de la suerte se alistó en la expedición de Barba; asistió al sitio y toma de México; vino después a la Nueva Galicia en compañía de Guzmán; salió luego con Oñate, ya habilitado con escribano de la expedición, y al fin se asentó como vecino en el pueblo de Tlaxochimaco, situado, como todos lo saben, en la raya de los actuales estados de Jalisco y Zacatecas (Salado, en prensa: 9).

El nombre es muy común; de hecho, Juan Pérez es paradigma del nombre 1lano, y el protagonista narrador no hace otra cosa que enfatizar la llaneza de su vida, de sus virtudes y de su apelativo, hasta que el lector se entera muy pronto de que el segundo apellido sigue siendo el mismo de su antepasado: de la Llana, explícita expresión de la llaneza.

Un personaje que comienza su narración diciendo su nombre y desplegando su genealogía es un paradigma de máximo respeto a la regla áurea de identidad entre nombre y personaje. Ello responde además al pacto y a los protocolos o procedimientos de la novela histórica clásica. Este género no desestabiliza y menos aun problematiza la relación nombre-personaje por un asunto de existencialista pérdida de identidad, sino en todo caso por suspenso o por algún otro mecanismo narrativo para hacer atractiva la acción: un personaje se hace pasar por otro para obtener una ventaja, por ejemplo.

La usurpación de personalidad es un tópico de la literatura universal y es, en efecto, muy común en la novela histórica, pues dicho género ubica las acciones en momentos de guerra, de aislamiento, de crisis, propicios para muchos desajustes más o menos duraderos. Por lo demás, la confusión de identidades es un conjunto amplio, dentro del cual se ubica el conjunto, más pequeño, de la usurpación de identidades. Dicha confusión puede asumir muchas formas y puede llegar hasta la nueva novela histórica, y es así como incluso en ejemplos como en el título El hombre que amaba a los perros, de Leonardo Padura, hay una confusión momentánea, pues este epíteto puede referirse a más de un personaje.

\section{El heredero de Cervantes y Galdós. Nombres característicos}

El nombre Juan Pérez de la Llana ya apunta a un rasgo en la onomástica y, de modo más general, en el estilo de Salado: la impronta de Miguel de Cervantes Saavedra y de Benito Pérez Galdós. El hispanismo en Salado no era una nostalgia, sino una toma de posición en el contexto de los forcejeos y reacomodos dentro de la incipiente y precaria élite literaria mexicana, reunida en la capital de la República, en la capital de Jalisco y en pocos sitios más.

En este contexto, la presencia de nombres al estilo cervantino ratificaban en Salado una vocación que no era necesariamente sólo tradicionalista, sino más bien militante de una causa activa con rasgos precisos: 1) confianza en el poder representativo del lenguaje, 2) confianza en la lengua española y sus tradiciones (tanto que el estilo de Salado podía incluir giros afines a un autor que, por grande que hubiera sido, ya tenía más de trescientos años de haber muerto) y 3) confianza en los recursos heredados de la tradición hispánica, que no excluía por cierto alguna cita en francés, alguna otra en latín y uno que otro vocablo en inglés.

Aun así, un censo de nombres propios en la narrativa breve y extensa de Salado arroja como resultado que los nombres más comunes son aquellos que Dieter Lamping clasifica como característicos, esto es, apelativos propios sin ninguna marca especial, salvo el hecho de que con relativa facilidad el lector los ubica como pertenecientes a 1) una región, 2) una época e incluso generación, 3) una cierta clase social y aun 4) una filiación ideológica (por ejemplo, religiosa).

El nombre Antonio Rojas (a la vez histórico y literario) demuestra todo esto: Rojas es un apellido más frecuente en el centro occidente del país que en otras regiones; no es tan específico de una época o una generación, pero por lo menos habla de una consolidación civil del nombre propio, que con solo dos términos identifica a una persona (la fama de este personaje contribuía a que nadie lo confundiera entonces con nadie más en la comarca y quizá en el país entero; en personas no famosas con nombre más o menos 
común, basta un tercer término como un segundo nombre de pila o el apellido materno para recuperar la regla áurea); los nombres sin título nobiliario o partículas como "don", "de" e "y" tienden a ser identificados como de una clase social llana, sea media o sea popular; el "Antonio" remite a una tradición onomástica de raíz católica, muy fuerte durante siglos y aun persistente en numerosas familias a la hora de registrar o bautizar a un vástago.

Una amplia mayoría de nombres propios en la narrativa de Salado cabe en este ejemplo.

\section{El autor de diálogos y de escenas}

El nerviosismo de la época tuvo un espejo en el nerviosismo de los géneros. Los diálogos y las escenas permitían a autores inquietos y atareados escribir piezas en relativamente poco tiempo, sin la concentración que en un cuento o novela exigen las descripciones, las ambientaciones, las acotaciones. Por lo menos, eso puede decirse de Salado Álvarez, quien remató los Episodios nacionales mexicanos con una larga obra de teatro en torno al drama de Querétaro y el Cerro de las Campanas, protagonizado por Maximiliano de Habsburgo.

En la introducción a Diálogos y escenas hay referencia al teatro para leerse, género que prosperó en el siglo XIX europeo y que con Salado tuvo a uno de los cultivadores más asiduos en México. También hay referencia al diálogo de los muertos, género que se remonta a Luciano y que en el mismo siglo XIX tuvo un florecimiento de la mano de pugnas filosóficas y políticas.

El teatro, sea para las tablas, sea para el sillón, ubica los nombres en un punto específico, a partir de la evidencia de que cada parlamento, a diferencia de mucha narrativa moderna, tiene que atribuirse claramente a un personaje específico, bien nominado.

En uno de sus diálogos, Salado tematiza precisamente la imposición de nombres y especifica por qué en un caso concreto no puede identificar a tres personajes con sus respectivos apelativos propios, sino con uno genérico, y con ello ejemplifica una regla básica de la identificación tanto en la vida fáctica como en el mundo posible del texto literario: la identificación puede hacerse con señales (el índice apunta a la persona), pronombres (ella, él), con sustantivos genéricos (como "el Maestro") y por supuesto con nombres propios:

Designaré a los interlocutores (por respetos humanos bien comprensibles) con los nombres del General, el Senador, el Maestro, pues ni tomé sus conversaciones por la taquigrafía y posible sería que atribuyera a los tres amigos opiniones que no fueran suyas, amén que no conviene en los tiempos que corren pecar de indiscreto revelando hechos u opiniones que quizás sus sostenedores deseaban guardar sin exponerlos a pública vergüenza por aquello que dijo el refrán: pon tu nombre en consejo y uno dirá que es blanco y otro dirá que es negro (Salado, en prensa: 9).

Este tono franco y práctico permea toda la nominalización en aquellos diálogos y escenas de Salado cuyos personajes son gente común. En los diálogos de los muertos los personajes son figuras históricas, y el solo nombre de cada una ya indica una época, una tendencia, una forma de pensar, una crisis política, un destino por lo común trágico. Dicho de otro modo, el nombre es sobre todo una gran síntesis, y su sola aparición evoca muchos sentidos posibles y exige una toma de posición por parte del lector; de hecho, aparece en el discurso para que el lector asuma una postura, y es así como el diálogo de los muertos es un género que deja definirse como una secuencia de parlamentos en los que cada personaje va presentando argumentos envueltos en anécdotas, descripciones, sentencias, citas, refranes, etcétera; los argumentos se proponen justificar las decisiones y la ideología de quien los emite.

\section{Conclusiones}

Cinco rasgos básicos se han descubierto aquí en el uso de los nombres dentro de la obra de Victoriano Salado Álvarez: 1) uso convencional en un texto innovador ("De autos"), 2) uso convencional en textos convencionales (como en "Oportunismo"), 3) uso convencional en novela histórica (los Episodios...), 4) influencia de la tradición onomástica de raíz cervantina y prolongación galdosiana en diversos textos y 5) empleo conforme a las convenciones del teatro en géneros de teatro para leerse (como los diálogos y las escenas).

El carácter convencional de un texto o un género no dice nada sobre el valor intrínseco de textos específicos y menos aun de géneros: sabemos bien que la literatura se construye con base en convenciones que se renuevan y que también se rompen. 
Una conclusión general deja enunciarse como sigue: el nombre propio es el identificador más estable y se emplea en relaciones humanas que van a durar. El nombre propio y la historia de su estabilización en las diferentes sociedades son indicadores de un estadio superior de convivencia y de un crecimiento de la población que tiende a ser regulado en un registro claro y distinto, con base en la regla áurea del nombre. Tanto entre personas como en lugares o sitios llega a producirse una desestabilización que en la vida fáctica debe resolverse de modo casuístico, esto es, caso por caso, situación por situación, mientras que en la literatura abre nuevas oportunidades para concebir argumentos con suspenso, clímax y desenlace. No se han detectado ejemplos de confusión de nombres como base en historias de Salado Álvarez.

Puede concluirse, en fin, que el nombre propio fue un factor de estabilidad en la obra del jalisciense, aun cuando él nació en una época en que el registro civil, convertido en parámetro desde las Leyes de Reforma de 1857, aún no se consolidaba como la base legal para la identidad de cada persona: él mismo se dijo alguna vez que le hubiera gustado llamarse Jerónimo, sin saber que así se llamaba, tal y como lo asienta su fe de bautismo:

La fe de bautismo, depositada en la parroquia, asienta:

Al margen izquierdo, en columna:

Teocaltiche

Gerónimo

Victoriano

$\mathrm{V}$.

$[\ldots]$

Victoriano parece no haber visto nunca la fe bautismal: en sus Memorias cuenta que Jerónimo era el del santo del día y que él lo hubiera preferido (34). El interés puede referirse a la imagen de san Jerónimo, hombre de letras, precursor del humanismo y amplio conocedor de las tradiciones griega y latina y, con ese carácter, enlace entre la Antigüedad y el Renacimiento. Aparte, san Jerónimo, cuyas polémicas con orígenes son célebres, brindaba a nuestro escritor la imagen del hombre de espíritu que se empeña en poner a prueba sus puntos de vista por medio de la discusión de altos vuelos (Vital, 2002:19-20).

Este pequeño dato anecdótico y biográfico nos confirma que los nombres propios son sumamente dinámicos y pueden mostrarse inestables e incluso problemáticos tanto en la vida fáctica como en la literatura.

\section{Referencias bibliográficas}

Borges, Jorge Luis (1989), “El desierto”, en Obras completas 1975-1985. Buenos Aires: EMECÉ.

Cosío D., José Ramón (2014). La justicia prometida. El Poder Judicial de la Federación de 1900 a 1910. México: Consejo Nacional para la Cultura y las Artes/Fondo de Cultura Económica.

Genette, Gérard (2001). Umbrales. México: Siglo XXI.

Hamon, Philippe (1989-1990), "Texto e ideología para una poética de la norma”, Criterios, nº. 25-28, enero de 1989diciembre de 1990., La Habana, págs. 66-94.

Lamping, Dieter (1983). Der Name in der Erzählung. Zur Poetik des Personennamens. Bonn: Bouvier.

Salado Álvarez, Victoriano (2013). Narrativa breve. Edc. crítico-hermenéutica establecida por Alberto Vital Díaz, Alejandro S. Shuttera et al. México: Universidad Nacional Autónoma de México-Instituto de Investigaciones Filológicas/ Universidad de Guadalajara/ El Colegio de Jalisco.

(2016). Diálogos y escenas. Edc. crítico-hermenéutica establecida por Alberto Vital Díaz, Alejandro S. Shuttera et al. México: Universidad Nacional Autónoma de México-Instituto de Investigaciones Filológicas/Universidad de Guadalajara/El Colegio de Jalisco.

(2018). Episodios nacionales mexicanos, I. De Santa Anna a la Reforma, 1. Edc. críticohermenéutica. México: Universidad Nacional Autónoma de México.

Saborit, Antonio (2003). El Mundo Ilustrado de Rafael Pérez Spíndola. México: Grupo CARSO.

Shakespeare, William (2016). Romeo y Julieta. Prefacio, trad. y notas de María Enriqueta González Padilla. México: Universidad Nacional Autónoma de México.

Vital, Alberto (2002). Un porfirista de siempre. Victoriano Salado Álvarez (1867-1931). México: Universidad Nacional Autónoma de México/Universidad Autónoma de Aguascalientes.

----, ----- (2013), "Introducción", en Victoriano Salado Álvarez. Narrativa breve. México: Universidad Nacional Autónoma de México, págs. XIX-XCV.

-----, -------- (2017), "Primeras menciones. Estrategias onomásticas en tres cuentos de Juan Rulfo" [inédito]. 
Vital, Alberto y Alfredo Barrios (coords.) (2017). Manual de onomástica de la literatura. México: Universidad Nacional Autónoma de México.

Vela, Arqueles (1990), "La señorita etcétera", en El café de nadie. México: ConACulTA (Lecturas Mexicanas 20. Tercera Serie), págs. 55-70. 